\title{
Análise dos instrumentos de avaliação na miopatia
}

\section{Clinical assessments analysis of myopathy}

\author{
Marina Brito Silva'1, Sabrina Kyoko de Paula Asa', Natasha Nicholson de Santa Maria', Érica Marques Zanella1, \\ Francis Meire Fávero², Marcia Maiumi Fukujima ${ }^{3}$, Sissy Veloso Fontes ${ }^{4}$, Acary Souza Bulle Oliveira 5 .
}

\section{RESUMO}

O objetivo deste estudo foi identificar e analisar os principais instrumentos utilizados na avaliação de pacientes com miopatia citados em artigos científicos publicados. Utilizou-se de revisão bibliográfica incluindo estudos publicados nos anos de 1966 a 2005 encontrados nas bases de dados MEDLINE, PUBMED, EMBASE, LILACS e SCIELO que utilizaram descritores na língua portuguesa (avaliação, escalas, fisioterapia, doenças musculares, reabilitação) e na inglesa (evaluation, scales, physical therapy, muscular diseases, rehabilitation). Foram encontrados 49 instrumentos de avaliação relacionados à força muscular, dor, equilíbrio, mobilidade e/ou locomoção, funcionalidade, atividades de vida diária, qualidade de vida e outros aspectos (eficácia da tosse, bem-estar, integração social, comunicação, coordenação olho-mão, raciocínio, auto-cuidado, fadiga e sono). Destas, apenas duas foram traduzidas para língua portuguesa e poucas foram elaboradas especificamente para pacientes com doenças neuromusculares. Sendo assim, tornam-se necessários estudos de tradução e validação destes instrumentos para a língua portuguesa falada no Brasil e elaboração de escalas que permitam avaliar e acompanhar o paciente ao longo da evolução da doença.

\section{Unitermos: Avaliação da deficiência, Escalas, Fisioterapia, Doenças Musculares, Reabilitação.}

Citação: Silva MB, Asa SKP, Maria NNS, Zanella EM, Fávero FM, Fukujima MM, Fontes SV, Oliveira ASB. Clinical assessments analysis of myopathy. Rev Neurocienc 2006; 14(2):029-043.

\section{SUMMARY}

The aim of the present study was to identify and analyse the main measures scales used in clinical assessment of patients with miopathies presented in published articles. We searched the MEDLINE, PUBMED, EMBASE, LILACS and SCIELO from 1966 to 2005 using the following keywords: evaluation, scales, physical therapy, muscular diseases, rehabilitation. It was found 49 measures scales related to strength, pain, balance, mobility and/or locomotor, funcionality, activities of daily living, quality of life and others aspects (cough, well being, personal/social, hearing and speech, eye/hand coordination, performance and practical reasoning, self care, fatigue and sleep). Only two scales were translated to portuguese and few were specifically elaborated for neuromuscular disease patients. Therefore, is needed further translate and validate measures scales in portuguese language spoken in Brazil and to develop new measures to provide patient clinical assessment.

\section{Keywords: Disability evaluation, Scales, Physical Therapy, Muscular Diseases, Rehabilitation.}

Citation. Silva MB, Asa SKP, Maria NNS, Zanella EM, Fávero FM, Fukujima MM, Fontes SV, Oliveira ASB. Análise dos instrumentos de avaliação na miopatia. Rev Neurocienc 2006; 14(1):029-043.

\section{INTRODUÇÃO}

O termo miopatia aplica-se a qualquer distúrbio que cause alterações patológicas, bioquímicas ou elétricas nas fibras musculares ou no tecido intersticial dos músculos esqueléticos, desde que não haja evidência de alterações secundárias aos processos orgânicos ou funcionais do sistema nervoso central ou periférico ${ }^{1}$. São doenças hereditárias ou adquiridas da musculatura esquelética que resultam na disfunção de qualquer dos constituintes deste tecido, levando ao aparecimento de sintomas isolados ou várias combinações de sinais e sintomas tais como fraqueza muscular, mialgia, câimbra, atrofia ou pseudohipertrofia muscular, miotonia e contratura muscular².

O objetivo principal dos programas de tratamento para pessoas com incapacidades decorrentes de miopatias é tornar possível que estas atinjam e mantenham um

Trabalho realizado: Universidade Federal de São Paulo - UNIFESP

1. Fisioterapeuta, Especialista em Intervenção Fisioterapêutica nas Doenças Neuromusculares pela UNIFESP

2. Fisioterapeuta, Mestre em Ciências pela UNIFESP

3. Neurologista, Doutora em Ciências pela UNIFESP

4. Fisioterapeuta, Professora de Educação Física, Doutora em Ciências pela UNIFESP

5. Neurologista, Professor Filiado da Disciplina de Neurologia do Departamento de Neurologia e Neurocirurgia da UNIFESP

Endereço para Correspondência: Sissy Veloso Fontes - R. Pedro de Toledo, 377, Vila Clementino - São Paulo-SP, CEP: 04039031 E-mail: sissyfontes@gmail.com 
nível ótimo de independência e função. Para que sejam alcançados os melhores resultados, torna-se necessária uma abordagem multidisciplinar, integrada e o uso de uma linguagem única na tomada de decisões. Com esse intuito, instrumentos de avaliação são necessários para que parâmetros sejam adotados no acompanhamento destes casos. O método de avaliação deve ser confiável, prático, reprodutível e adaptado às características culturais e sociais de cada grupo populacional ${ }^{3-5}$. Alguns parâmetros têm sido utilizados com freqüência para pacientes com miopatias, como medidas de força muscular (FM), amplitude de movimento articular (ADM), desempenho funcional ${ }^{3,4}$ e qualidade de vida relacionada à saúde ${ }^{6}$. No entanto, existem controvérsias na literatura sobre tais instrumentos, ou seja, não há um consenso sobre qual escala é a mais apropriada para os casos de miopatias.

Esse estudo teve como objetivo identificar e analisar os principais instrumentos utilizados na avaliação de pacientes com miopatia citados em artigos científicos publicados.

\section{MÉTODO}

Para identificação e caracterização dos instrumentos de avaliação de pacientes com miopatia, utilizou-se de revisão bibliográfica, sendo incluídos artigos científicos publicados nos anos de 1966 a 2005 encontrados nas bases de dados MEDLINE, PUBMED, EMBASE, LILACS e SCIELO que utilizaram descritores na língua portuguesa (avaliação, escalas, fisioterapia, doenças musculares, reabilitação) e na inglesa (evaluation, scales, physical therapy, muscular diseases, rehabilitation) que apresentavam algum instrumento de avaliação e, por busca manual das referências citadas nos artigos encontrados. A estratégia de busca utilizada tanto na MEDLINE, LILACS quanto SCIELO foi: descritor de assunto= "DISTROFIA MUSCULAR" AND Aspectos $=$ Reabilitação $(/ R H)$ AND Espécie $=$ Humanos, na PUBMED foi muscular dystrophy, scale e limits: humans e na EMBASE foi "myopathy"/exp OR 'myopathy' AND scale AND [humans] / lim 1966 a 2005.

Após a revisão bibliográfica foram excluídos os estudos que utilizaram instrumentos de avaliação da função respiratória, experimentos com animais e os que não utilizavam nenhuma medida de avaliação.

\section{RESULTADOS}

Foram encontrados 49 instrumentos de avaliação utilizados em diferentes tipos de miopatias. Destes, 11 são relacionados à força muscular (quadro 1); 3 a dor, 1 ao equilíbrio e 11 a mobilidade e/ou locomoção (quadro 2); 3 a funcionalidade para membros superiores (MMSS) e 9 as atividades de vida diária - AVD (quadro 3), 6 a qualidade de vida (quadro 4) e 5 a outros aspectos (quadro 5).

\section{DISCUSSÃO}

Foram poucos os estudos encontrados sobre fisioterapia em pacientes com miopatia. Estes incluíam medidas relacionadas aos déficits (impairment) como força muscular, avaliação da dor, equilíbrio e ADM; relacionadas às incapacidades (disabilities) como mobilidade e/ou locomoção, funcionalidade para MMSS e AVD; relacionadas às desvantagens (handicap) como as escalas de diferentes domínios e, medidas de qualidade de vida relacionada à saúde. Estas medidas têm sido preconizadas em vários estudos sobre intervenção fisioterapêutica para pacientes neurológicos e em outras áreas das Ciências da Saúde.

\section{Avaliação de força muscular}

Uma das características clínicas mais freqüentes em miopatias é a diminuição da força muscular, que pode se instalar de diferentes maneiras, por exemplo, ter predomínio distal ou proximal. Devido as miopatias terem características progressivas, o indivíduo pode tornar-se cada vez mais limitado e dependente em decorrência, dentre outros fatores, da perda da força. Assim é necessário, portanto, a avaliação periódica e sistematizada deste sintoma.

Há divergências na literatura quanto ao uso do teste de força muscular manual como um instrumento de mensuração ${ }^{47}$. Embora este seja visto como uma avaliação clínica padronizada da progressão das doenças musculares, não está claro se é o método mais relevante e apropriado ${ }^{48}$. Qualquer mensuração de força muscular deve ser reprodutível por diferentes avaliadores ${ }^{4}$.

Alguns autores consideram a escala do Medical Research Council (MRC) um método estabelecido e confiável, utilizado para avaliar a força muscular em

Quadro 1. Tabulação das escalas de força muscular e equações de força muscular em relação ao nome e sigla, referência bibliográfica, componentes e doenças neuromusculares.

\begin{tabular}{|c|c|c|c|}
\hline Escala & Referências bibliográficas & Componentes & $\begin{array}{c}\text { Doenças } \\
\text { Neuromusculares } \\
\end{array}$ \\
\hline $\begin{array}{l}\text { 1. Medical Research } \\
\text { Council (MRC) }\end{array}$ & $\begin{array}{l}\text { Medical Research Council. } \\
\text { Aids to the Investigation of } \\
\text { Peripheral Nerve Injuries. War } \\
\text { Memorandum (revised } 2^{\text {nd }} \text { edi- } \\
\text { tion). London, HMSO, } 1943^{7}\end{array}$ & $\begin{array}{l}\text { Pontuação (de } 0 \text { a 5): } \\
\text { 0: paralisia total; } \\
\text { 1: contração visível ou palpável; } \\
\text { 2: movimento ativo, arco de movimento completo com a } \\
\text { gravidade eliminada, } \\
\text { 3: movimento ativo, arco de movimento completo contra } \\
\text { a gravidade, } \\
\text { 4: movimento ativo, arco de movimento completo, contra } \\
\text { uma moderada resistência, } \\
\text { 5: normal, arco de movimento completo contra resistência }\end{array}$ & DMD, DMB, AEP \\
\hline
\end{tabular}


Cont. Quadro 1. Tabulação das escalas de força muscular e equações de força muscular em relação ao nome e sigla, referência bibliográfica, componentes e doenças neuromusculares.

\begin{tabular}{|c|c|c|c|}
\hline Escala & Referências bibliográficas & Componentes & $\begin{array}{c}\text { Doenças } \\
\text { Neuromusculares }\end{array}$ \\
\hline $\begin{array}{l}\text { 2. Escala do MRC mo- } \\
\text { dificada por Brooke }\end{array}$ & $\begin{array}{l}\text { Brooke MH, Griggs RC, Mendell } \\
\text { JR, Fenichel GM, Shumate JB, } \\
\text { Pellegrino RJ. Clinical trial in } \\
\text { Duchenne dystrophy: the de- } \\
\text { sign of the protocol. Muscle \& } \\
\text { Nerve } 1981 ; 4: 186-97^{4}\end{array}$ & $\begin{array}{l}\text { Pontuação (de } 0 \text { a } 5 \text {, cada pontuação contém subdivisões que } \\
\text { visam quantificar de modo mais sensível o grau de força) } \\
\text { 5: força normal } \\
\text { 5-: fraqueza muscular não confirmada } \\
4 \text { S: o mesmo que } 4 \text { mas mais forte que o músculo referência } \\
\text { 4: o músculo é fraco mas move a articulação contra a } \\
\text { gravidade e alguma resistência } \\
4 \text { W: O mesmo que } 4 \text { mas mais fraco que o músculo referência } \\
3+: \text { o músculo é capaz de vencer uma resistência transitória, } \\
\text { mas colapsa abruptamente. Este grau de fraqueza é difícil de } \\
\text { descrever, mas este músculo é capaz de mover a articulação } \\
\text { contra a gravidade e uma quantidade pequena adicional de } \\
\text { resistência. Não deve ser usado para músculos capazes de } \\
\text { sustentar resistência através de toda ADM } \\
\text { 3-: músculo move a articulação contra a gravidade, mas } \\
\text { não ao longo de toda a ADM mecânica. } \\
\text { 2: músculo move a articulação sem ação da gravidade } \\
\text { 1: um esboço de contração é visto ou sentido no músculo } \\
0: \text { sem movimento }\end{array}$ & $\begin{array}{l}\text { DMD, DFSH, distrofia } \\
\text { miotônica, DMB, dis- } \\
\text { trofia cinturamembros, } \\
\text { miopatia inflamatória } \\
\text { idiopática do adulto }\end{array}$ \\
\hline $\begin{array}{l}\text { 3.Escala do MRC mo- } \\
\text { dificada por Daniels } \\
\text { \& Worthingham }\end{array}$ & $\begin{array}{l}\text { Daniels L, Worthingham C. } \\
\text { Muscle testing: techniques } \\
\text { of manual examination. } 5^{\text {th }} \text { ed. } \\
\text { Philadelphia, PA: WB Saun- } \\
\text { ders Co. } 1986^{8}\end{array}$ & $\begin{array}{l}\text { Pontuação (de } 0 \text { a } 5 \text {, cada pontuação contém subdivisões que } \\
\text { visam quantificar de modo mais sensível o grau de força) } \\
\text { 5: força normal } \\
\text { 5-: fraqueza muscular não confirmada } \\
\text { 4+: inabilidade para resistir contra resistência máxima em } \\
\text { ADM completa } \\
\text { 4: habilidade para resistir contra resistência moderada } \\
\text { em ADM completa } \\
\text { 4-: habilidade para resistir contra resistência mínima em } \\
\text { ADM completa } \\
\text { 3+: habilidade para mover em ADM completa contra a } \\
\text { gravidade e para resistir contra resistência mínima em ADM } \\
\text { incompleta, então a contração pára abruptamente. } \\
\text { 3: habilidade para mover em ADM completa contra a } \\
\text { gravidade } \\
\text { 3-: habilidade para mover em mais da metade da ADM } \\
\text { contra a gravidade } \\
\text { 2+: habilidade para mover em menos da metade da ADM } \\
\text { contra a gravidade } \\
\text { 2: habilidade para mover em ADM completa sem ação } \\
\text { da gravidade } \\
\text { 2-: habilidade para mover em qualquer ADM sem ação } \\
\text { da gravidade } \\
\text { 1: um esboço de contração é visto ou sentido no músculo } \\
\text { 0: sem contração palpável }\end{array}$ & DFSH, DMD \\
\hline $\begin{array}{l}\text { 4. Escala de gradu- } \\
\text { ação da força mus- } \\
\text { cular elaborada por } \\
\text { Kendall }\end{array}$ & $\begin{array}{l}\text { Kendall FP, McCreary EK, } \\
\text { Provance PG. Muscles: testing } \\
\text { and function } 4^{\text {th }} \text { ed. Baltimore: } \\
\text { Williams \& Wilkins, } 1993^{9}\end{array}$ & 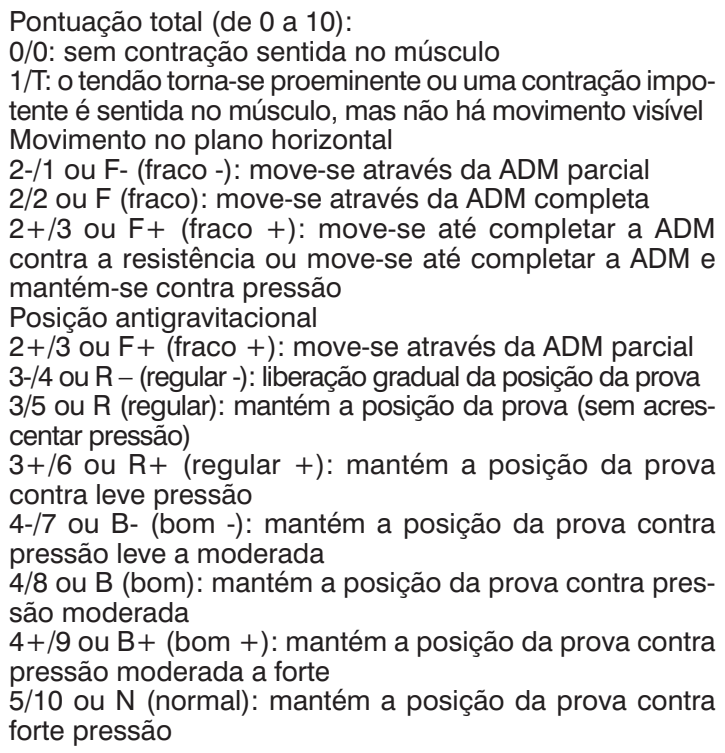 & $\begin{array}{l}\text { Miopatia inflamatória } \\
\text { idiopática da criança, } \\
\text { miopatia inflamatória } \\
\text { idiopática do adulto }\end{array}$ \\
\hline
\end{tabular}


Cont. Quadro 1. Tabulação das escalas de força muscular e equações de força muscular em relação ao nome e sigla, referência bibliográfica, componentes e doenças neuromusculares.

\begin{tabular}{|c|c|c|c|}
\hline Escala & Referências bibliográficas & Componentes & $\begin{array}{c}\text { Doenças } \\
\text { Neuromusculares }\end{array}$ \\
\hline $\begin{array}{l}\text { 5. Escala do MRC mo- } \\
\text { dificada por Bakker }\end{array}$ & $\begin{array}{l}\text { Bakker JPJ, de Groot IJM, } \\
\text { Beelen A, Lankhorst GJ. Pre- } \\
\text { dictive factors of cessation of } \\
\text { ambulation in patients with } \\
\text { DMD. Am J Phys Med Rehabil. } \\
2002 ; 81: 906-12^{10}\end{array}$ & $\begin{array}{l}\text { Pontuação (de } 0 \text { a } 5 \text {, com subdivisões que visam quanti- } \\
\text { ficar de modo mais sensível o grau de força) } \\
\text { 5: força normal } \\
\text { 5-: fraqueza muscular não confirmada } \\
\text { 4: o músculo é fraco mas move a articulação contra a } \\
\text { gravidade e alguma resistência } \\
\text { 3+: o músculo é capaz de vencer uma resistência transitória, } \\
\text { mas colapsa abruptamente. Este grau de fraqueza é difícil de } \\
\text { descrever, mas este músculo é capaz de mover a articulação } \\
\text { contra a gravidade e uma quantidade pequena adicional de } \\
\text { resistência. Não deve ser usado para músculos capazes de } \\
\text { sustentar resistência através de toda ADM } \\
\text { 3-: músculo move a articulação contra a gravidade, mas } \\
\text { não ao longo de toda a ADM mecânica. } \\
\text { 2: músculo move a articulação sem ação da gravidade } \\
\text { 1: um esboço de contração é visto ou sentido no músculo } \\
\text { 0: sem movimento }\end{array}$ & DMD \\
\hline $\begin{array}{l}\text { 6. Muscular Disability } \\
\text { Rating Scale (MDRS) }\end{array}$ & $\begin{array}{l}\text { Mathieu J, de Braekeleer MD, } \\
\text { Prévost C, Boily C. Myotonic } \\
\text { dystrophy: clinical assessment } \\
\text { of muscular disability in na iso- } \\
\text { lated population with presumed } \\
\text { homogeneous mutation. Neu- } \\
\text { rology 1992; 42:203-8 }{ }^{11}\end{array}$ & $\begin{array}{l}5 \text { itens com pontuação de } 1 \text { a } 5 \text { : } \\
\text { 1: sem sinais clínicos } \\
\text { 2: sinais mínimos (miotonia, degeneração dos músculos tem- } \\
\text { porais e mandibulares, fraqueza da musculatura facial, dege- } \\
\text { neração do músculo esternomastoideo, ptose, fala anasalada, } \\
\text { sem fraqueza distal exceto dos flexores dos dedos), } \\
\text { 3: fraqueza distal (sem fraqueza proximal exceto do } \\
\text { tríceps braquial) } \\
\text { 4: fraqueza proximal leve ou moderada } \\
\text { 5: fraqueza proximal severa (confinado a cadeira de rodas } \\
\text { por curtas ou longas distâncias) }\end{array}$ & Distrofia miotônica \\
\hline $\begin{array}{l}\text { 7. Muscular Impair- } \\
\text { ment Rating Scale } \\
\text { (MIRS) }\end{array}$ & $\begin{array}{l}\text { Mathieu J, Boivin H, Meunier } \\
\mathrm{D} \text {, Gaundreault M, Bégin P. As- } \\
\text { sessment of a disease-specific } \\
\text { muscular impairment rating } \\
\text { scale in myotonic dystrophy. } \\
\text { Neurology } 2001 ; 56: 336-40^{12}\end{array}$ & $\begin{array}{l}\text { Paciente é classificado em um dos } 5 \text { itens: } \\
\text { 1: sem prejú́zo muscular (sem sinais de fraqueza) } \\
\text { 2: sinais mínimos (miotonia degeneração dos músculos } \\
\text { temporais e mandibulares, fraqueza facial, fraqueza dos } \\
\text { flexores do pescoço, ptose, fala nasal, sem fraqueza distal } \\
\text { com exceção dos flexores dos dedos) } \\
\text { 3: fraqueza distal (sem fraqueza proximal exceto dos } \\
\text { extensores de cotovelo) } \\
\text { 4: leve a moderada fraqueza proximal } \\
\text { 5: severa fraqueza proximal (MRC } \leq 3 / 5 \text { ) }\end{array}$ & Distrofia miotônica \\
\hline $\begin{array}{l}\text { 8. Average Muscle } \\
\text { Score (AMS) }\end{array}$ & $\begin{array}{l}\text { Brooke MH, Fenichel GM, } \\
\text { Griggs RC, Mendell JR, Moxley } \\
\text { R, Miller JP, et al. Clinical investi- } \\
\text { gation in DMD: 2. determination } \\
\text { of the "power" of therapeutic tri- } \\
\text { als based on the natural history. } \\
\text { Muscle nerve. 1983;6:91-103 } 13\end{array}$ & $\begin{array}{l}\text { A escala MRC foi convertida em um sistema de } 0-10 \\
\text { pontos }(0=0 ; 5=10) \text {. A AMS é a média numérica de } 34 \\
\text { músculos testados } \\
\text { Pontuação total (de } 0 \text { a 10) } \\
\text { Quanto menor a pontuação, maior a fraqueza }\end{array}$ & $\begin{array}{l}\text { Distrofia cintura } \\
\text { membros }\end{array}$ \\
\hline $\begin{array}{l}\text { 9. Total Motor Score } \\
\text { (TMS) }\end{array}$ & $\begin{array}{l}\text { Nair KPS, Vasanth A, Gourie- } \\
\text { Devi M,Taly AB. Disabilities in } \\
\text { children with DMD: a profile. J } \\
\text { Rehabil Med } 2001 ; 33: 147-9^{14}\end{array}$ & $\begin{array}{l}\text { Soma da pontuação de } 16 \text { músculos testados através do MRC } \\
\text { Pontuação total (de } 0 \text { a } 80 \text { ) } \\
\text { 0: ausência de movimento; } \\
\text { 80: força normal nos } 16 \text { músculos }\end{array}$ & DMD \\
\hline $\begin{array}{l}\text { 10. Total } \\
\text { Muscle Score }\end{array}$ & $\begin{array}{l}\text { Mathieu J, Boivin H, Meunier } \\
\text { D, Gaundreault M, Bégin P. As- } \\
\text { sessment of a disease-specific } \\
\text { muscular impairment rating } \\
\text { scale in myotonic dystrophy. } \\
\text { Neurology 2001;56:336-40 12 } \\
\text { Florence JM, Pandya S, King } \\
\text { WM, Robison JD, Signore } \\
\text { LC, Wentzell M, et al. Clinical } \\
\text { trials in Duchenne dystrophy. } \\
\text { Standardization and reliability } \\
\text { of evaluation procedures. Phys } \\
\text { Ther 1984;64(1):41-5 } 15 \\
\text { Sultan SM. Clinical assessment } \\
\text { in adult onset idiopathic inflam- } \\
\text { matory myopathy. Curr Opin } \\
\text { Rheumatol 2004;16:668-72 }{ }^{16}\end{array}$ & $\begin{array}{l}\text { Soma da pontuação modificada da força muscular dos } \\
\text { grupos musculares testados dependendo da escolha } \\
\text { do examinador }\end{array}$ & $\begin{array}{l}\text { DMD, DMB, miopatia } \\
\text { inflamatória idiopáti- } \\
\text { ca do adulto, distro- } \\
\text { fia miotônica }\end{array}$ \\
\hline $\begin{array}{l}\text { 11. Total Muscle } \\
\text { Strength (\%MRC) }\end{array}$ & $\begin{array}{l}\text { Scott OM, Hyde SA, Goddard, } \\
\text { C, Dubowitz V. Quantitation of } \\
\text { muscle function in children: a } \\
\text { prospective study in DMD. Mus- } \\
\text { cle \& Nerve } 1982 ; 5: 291-301^{17}\end{array}$ & $\begin{array}{l}\text { Mensura de forma global a \% de força do indivíduo, utili- } \\
\text { zando a seguinte fórmula: } \\
\text { Soma das pontuações de FM } \times 100 \\
\text { Número de músculos testados } \times 5\end{array}$ & DMD \\
\hline
\end{tabular}

DMD: distrofia muscular de Duchenne, DMB: distrofia muscular de Becker, AEP: amiotrofia espinhal progressiva, DFSH: distrofia fascioescapuloumeral 
Quadro 2. Tabulação das escalas de dor, equilíbrio e mobilidade e/ou locomoção em relação ao nome e sigla, referência bibliográfica, componentes e doenças neuromusculares

\begin{tabular}{|c|c|c|c|}
\hline Escala & Referências bibliográficas & Componentes & $\begin{array}{c}\text { Doenças } \\
\text { Neuromusculares }\end{array}$ \\
\hline $\begin{array}{l}\text { 1. Graded Chronic } \\
\text { Pain Scale }\end{array}$ & & $\begin{array}{l}\text { Itens referentes à intensidade da dor } \\
0: \text { sem dor } \\
\text { 10: a pior dor possível }\end{array}$ & $\begin{array}{l}\text { Poliomiosite, dermato- } \\
\text { miosite, distrofias mus- } \\
\text { culares, miopatias meta- } \\
\text { bólicas, miastenia grave, } \\
\text { síndrome Eaton-Lambert, } \\
\text { CMT, Guillian-Barré }\end{array}$ \\
\hline $\begin{array}{l}\text { 2. Neuropathic pain } \\
\text { scale (NPS) modifi- } \\
\text { cada por Jensen }\end{array}$ & & $\begin{array}{l}\text { Descritores para tipos de dor (intensa, cortante, } \\
\text { queimação,enfadonha, gelada, sensível, coceira, de- } \\
\text { sagradável, profunda, superficial, cansativa, doentia, } \\
\text { terrível, punição) } \\
\text { Pontuação para cada descritor } \\
\text { 0: nenhuma sensação } \\
\text { 10: a sensação mais intensa imaginável }\end{array}$ & $\begin{array}{l}\text { Poliomiosite, dermato- } \\
\text { miosite, distrofias mus- } \\
\text { culares, miopatias meta- } \\
\text { bólicas, miastenia grave, } \\
\text { síndromeEaton-Lambert, } \\
\text { CMT, Guillian-Barré }\end{array}$ \\
\hline $\begin{array}{l}\text { 3. Brief pain inven- } \\
\text { tory (BPI) modificado } \\
\text { por Tyler }\end{array}$ & $\begin{array}{l}\text { Tyler EJ, Jensen MP, Engel } \\
\text { JM. The reliability and valid- } \\
\text { ity of pain interference mea- } \\
\text { sures in persons with cerebral } \\
\text { palsy. Arch Phys Med Rehabil } \\
2002 ; 83: 236-9^{20}\end{array}$ & $\begin{array}{l}10 \text { itens (atividade geral, humor, mobilidade, trabalho } \\
\text { doméstico e ocupacional dentro e fora de casa, relacio- } \\
\text { namento interpessoal, sono, satisfação com a vida, auto- } \\
\text { cuidado, atividades recreacionais e atividades sociais) } \\
\text { Pontuação de cada item avaliando a interferência da } \\
\text { dor nestas atividades: } \\
\text { 0: sem interferência } \\
\text { 10: interferência completa }\end{array}$ & $\begin{array}{l}\text { Poliomiosite, dermato- } \\
\text { miosite, distrofias mus- } \\
\text { culares, miopatias meta- } \\
\text { bólicas, miastenia grave, } \\
\text { síndromeEaton-Lambert, } \\
\text { CMT, Guillian-Barré }\end{array}$ \\
\hline $\begin{array}{l}\text { 4. Berg's } \\
\text { Balance Scale }\end{array}$ & $\begin{array}{l}\text { Miyamoto ST, Junior IL, Berg } \\
\text { KO, Ramos LR, Natour Jz. } \\
\text { Brazilian version of the Berg } \\
\text { Balance Scale. J Med Biol Res. } \\
\text { 2004; 37(9): 1411-1421 } 21\end{array}$ & $\begin{array}{l}14 \text { testes funcionais sobre a qualidade do movimento: } \\
\text { - posição sentada para posição em pé } \\
\text { - permanecer em pé sem apoio } \\
\text { - permanecer sentado sem apoio } \\
\text { - posição em pé para posição sentada } \\
\text { - transferências } \\
\text { - permanecer em pé com os olhos fechados } \\
\text { - permanecer em pé com os pés juntos } \\
\text { - alcançar a frente com os braços estendidos } \\
\text { - pegar um objeto do chão } \\
\text { - virar-se para olhar para trás } \\
\text { - girar } 360^{\circ} \\
\text { - posicionar os pés alternadamente no degrau } \\
\text { - permanecer em pé com um pé a frente } \\
\text { - permanecer em pé sobre um pé } \\
\text { Pontuação para cada item (escala ordinal de } 0 \text { a 4) }\end{array}$ & $\begin{array}{l}\text { Distrofia miotônica, dis- } \\
\text { trofia muscular proximal, } \\
\text { distrofia muscular distal }\end{array}$ \\
\hline $\begin{array}{l}\text { 5. Hammersmith Lo- } \\
\text { comotor Ability Scale }\end{array}$ & $\begin{array}{l}\text { Scott OM, Hyde SA, Goddard, } \\
\text { C, Dubowitz V. Quantitation of } \\
\text { muscle function in children: a pro- } \\
\text { spective study in DMD. Muscle \& } \\
\text { Nerve. 1982; 5:291-301 }{ }^{17}\end{array}$ & $\begin{array}{l}20 \text { itens } \\
\text { Pontuação para cada item (de } 0 \text { a 2): } \\
0: \text { incapacidade de realizar tarefa } \\
\text { 1: realiza com auxílio } \\
\text { 2: realiza tarefa completamente } \\
\text { Pontuação total (de } 0 \text { a } 40 \text { ) }\end{array}$ & DMD \\
\hline 6. Functional Tests & $\begin{array}{l}\text { Allsop K, Ziter FA. Loss of } \\
\text { strength and functional decline } \\
\text { in Duchenne's Dystrophy. Arch } \\
\text { Neurol 1981;38:406-11 } 22\end{array}$ & $\begin{array}{l}\text { Tempo (em seg) para realização de } 6 \text { atividades: } \\
\text { 1: subir } 8 \text { degraus (cada um com } 20 \mathrm{~cm} \text { de altura) sem } \\
\text { usar o corrimão } \\
\text { 2: levantar a partir do supino } \\
\text { 3: subir degraus usando o corrimão } \\
\text { 4: passar de supino para gato } \\
\text { 5: passar de supino para sentado } \\
\text { 6: andar } 750 \mathrm{~cm} \text { ( } 25 \text { pés) } \\
\text { Tempo }>60 \text { seg: paciente falhou na tarefa }\end{array}$ & DMD \\
\hline $\begin{array}{l}\text { 7. Locomotor Sub- } \\
\text { scale Griffiths' Men- } \\
\text { tal Developmental } \\
\text { Scales }\end{array}$ & $\begin{array}{l}\text { Hanson R, Albridge-Smith D, } \\
\text { Hume W. Achivements on items } \\
\text { of the Griffiths Scales: } 1980 \\
\text { compared with 1950. Child care } \\
\text { health dev. 11:91-104 }{ }^{23}\end{array}$ & $\begin{array}{l}86 \text { itens }-48 \text { itens até } 2 \text { anos } \\
-6 \text { itens para } 3 \text { anos } \\
-6 \text { itens para } 4 \text { anos } \\
-6 \text { itens para } 5 \text { anos } \\
-6 \text { itens para } 6 \text { anos } \\
-6 \text { itens para } 7 \text { anos } \\
-8 \text { itens para } 8 \text { anos } \\
\text { Item é pontuado apenas se realizado conforme o manual } \\
\text { Pontuação para cada mês: } \\
\text { - Se de } 1 \text { a } 2 \text { anos: soma dos itens no ano } \div 2 \\
\text { - Se de } 3 \text { a } 8 \text { anos: soma dos itens no ano x } 2 \\
\text { Coeficiente de locomoção (CL) em \%: } \\
\text { soma das pontuações (meses) para cada ano } \\
\text { idade }\end{array}$ & DMD \\
\hline
\end{tabular}


Cont. Quadro 2. Tabulação das escalas de dor, equilíbrio e mobilidade e/ou locomoção em relação ao nome e sigla, referência bibliográfica, componentes e doenças neuromusculares

\begin{tabular}{|c|c|c|c|}
\hline Escala & Referências Bibliográficas & Componentes & $\begin{array}{c}\text { Doenças } \\
\text { Neuromusculares }\end{array}$ \\
\hline $\begin{array}{l}\text { 8. Time Functional } \\
\text { Score (TFS) }\end{array}$ & $\begin{array}{l}\text { Nair KPS, Vasanth A, Gourie- } \\
\text { Devi M,Taly AB. Disabilities in } \\
\text { children with DMD: a profile. J } \\
\text { Rehabil Med } 2001 ; 33: 147-9^{14}\end{array}$ & $\begin{array}{l}\text { Tempo (em seg) para realizar } 3 \text { tarefas: } \\
\text { - levantar a partir do supino, } \\
\text { - subir } 4 \text { degraus, } \\
\text { - correr ou andar } 30 \text { pés, o mais rápido possível. } \\
\text { Pontuação de acordo com o tempo gasto para realizar } \\
\text { cada tarefa (de } 0 \text { a } 6 \text { ) } \\
\text { 0: tempo > } 120 \text { seg, } \\
\text { 1: tempo entre } 100 \text { e } 120 \mathrm{seg}, \\
\text { 2: tempo entre } 80 \text { e } 100 \mathrm{seg}, \\
\text { 3: tempo entre } 60 \text { e } 80 \mathrm{seg}, \\
\text { 4: tempo entre } 40 \text { e } 60 \mathrm{seg}, \\
\text { 5: tempo entre } 20 \text { e } 40 \text { seg, } \\
\text { 6: tempo menor que } 20 \text { seg. } \\
\text { Pontuação total (de } 0 \text { a 18): soma das pontuações } \\
\text { obtidas nas três tarefas }\end{array}$ & DMD \\
\hline $\begin{array}{l}\text { 9. Teste de função } \\
\text { muscular }\end{array}$ & $\begin{array}{l}\text { Ahlstrom G, Gunnarson LG. } \\
\text { Disability and quality of life } \\
\text { in individuals with muscular } \\
\text { dystrophies. Scand J Rehabil } \\
\text { Med 1996;28:147-57 } 24\end{array}$ & $\begin{array}{l}18 \text { tarefas analisadas } \\
\text { Pontuação para cada tarefa (de } 0 \text { a 4) } \\
\text { 0: normal } \\
\text { 4: falha ao realizar a tarefa } \\
\text { Pontuação total: índice de mobilidade (de } 0 \text { a 100) } \\
\text { 0: função normal } \\
\text { 100: indivíduo falhou nos testes }\end{array}$ & $\begin{array}{l}\text { Distrofia miotônica, } \\
\text { miopatia distal heredi- } \\
\text { tária, distrofia muscular } \\
\text { de cintura-membros, } \\
\text { DFSH,DMB, distrofia } \\
\text { de Emery Dreifuss }\end{array}$ \\
\hline $\begin{array}{l}\text { 10. Motor function } \\
\text { measure scale (MFM) } \\
\text { for neuromuscular } \\
\text { disease }\end{array}$ & $\begin{array}{l}\text { Bérard C, Payan C, Hodgkin- } \\
\text { son I, Fian J. A motor function } \\
\text { measure scale for neuromuscu- } \\
\text { lar diseases. Construction and } \\
\text { validation study. Neuromuscul } \\
\text { Disord } 2005 ; 15(7): 463-70^{25}\end{array}$ & $\begin{array}{l}32 \text { itens em dimensões (posição em pé e transferência, } \\
\text { função motora axial e proximal, função motora distal) } \\
\text { Pontuação total (de } 0 \text { a 96) } \\
\text { Pontuação genérica } \\
0 \text { : não inicia movimento ou não é capaz de manter a } \\
\text { postura inicial } \\
\text { 1: completa o exercício parcialmente } \\
\text { 2: completa o exercício com compensações, vagaro- } \\
\text { samente ou de forma desajeitada } \\
\text { 3: completa o exercício conforme padronizado }\end{array}$ & $\begin{array}{l}\text { DMD, DMB, distrofia } \\
\text { muscular cintura mem- } \\
\text { bros, DFSH, distrofia } \\
\text { miotônica, miopatia con- } \\
\text { gênita, distrofia muscular } \\
\text { congênita, AEP, neuro- } \\
\text { patia hereditária }\end{array}$ \\
\hline 11. Escala de Vignos & $\begin{array}{l}\text { Vignos PJ, Archibald KC. Main- } \\
\text { tenance of ambulation in child- } \\
\text { hood muscular dystrophy J } \\
\text { Chron Dis 1960;12(2):273-89 }{ }^{26}\end{array}$ & $\begin{array}{l}\text { Paciente é classificado em um dos } 10 \text { itens: } \\
\text { 1: dificuldade evidente na postura e marcha mas anda } \\
\text { e sobe escadas sem auxílio, } \\
\text { 2: anda mas sobe escadas apenas com ajuda de } \\
\text { corrimão, } \\
\text { 3: anda mas sobe } 8 \text { degraus padronizados com auxílio } \\
\text { de corrimão em mais de } 25 \text { seg, } \\
\text { 4: anda mas não é capaz de subir degraus, } \\
\text { 5: anda sem assistência mas não consegue levantar } \\
\text { da cadeira ou subir degraus, } \\
\text { 6: anda apenas com auxílio de órteses } \\
\text { 7: Na CR: senta ereto, pode tocar a CR e realizar AVDs } \\
\text { na cama e sentado, } \\
\text { 8: Na CR: senta ereto, é incapaz de realizar AVDs na } \\
\text { cama ou sentado sem auxílio; } \\
\text { 9: Na CR: senta ereto apenas com apoio. É capaz de } \\
\text { realizar apenas mínimas AVDs. } \\
\text { 10: Na cama, é incapaz de realizar AVDs sem auxílio }\end{array}$ & Distrofias musculares \\
\hline $\begin{array}{l}\text { 12. Escala de Vignos } \\
\text { modificada por Vignos }\end{array}$ & $\begin{array}{l}\text { Vignos PJ, Archibald KC, } \\
\text { Spencer G. Management of } \\
\text { progressive muscular dys- } \\
\text { trophy of childhood. JAMA } \\
1963 ; 184: 89-110^{27}\end{array}$ & $\begin{array}{l}\text { Paciente é classificado em um dos } 10 \text { itens: } \\
\text { 1: anda e sobe escadas sem auxílio, } \\
\text { 2: anda e sobe escadas com ajuda de corrimão, } \\
\text { 3: anda e sobe escadas vagarosamente, comajuda de cor- } \\
\text { rimão (mais de } 12 \text { seg para } 4 \text { degraus padronizados), } \\
\text { 4: anda sem assistência, levanta da cadeira mas não } \\
\text { consegue subir escadas, } \\
\text { 5: anda sem assistência mas não consegue levantar } \\
\text { da cadeira ou subir escadas, } \\
\text { 6: anda apenas com auxílio ou anda independente- } \\
\text { mente com tutor longo, } \\
\text { 7: anda com tutor longo mas requer auxílio para manter } \\
\text { o equilíbrio, } \\
\text { 8: permanece em ortostatismo com o tutor longo mas } \\
\text { não é capaz de andar sem auxílio, } \\
\text { 9: está confinado à CR } \\
\text { 10: confinado ao leito }\end{array}$ & $\begin{array}{l}\text { DMD, DFSH, distrofia } \\
\text { miotônica, DMB, distrofia } \\
\text { cintura membros, miopa- } \\
\text { tia congênita, CMT, ataxia } \\
\text { de Friedrich }\end{array}$ \\
\hline
\end{tabular}


Cont. Quadro 2. Tabulação das escalas de dor, equilíbrio e mobilidade e/ou locomoção em relação ao nome e sigla, referência bibliográfica, componentes e doenças neuromusculares

\begin{tabular}{|c|c|c|c|}
\hline Escala & Referências bibliográficas & Componentes & $\begin{array}{l}\text { Doenças } \\
\text { Neuromusculares }\end{array}$ \\
\hline $\begin{array}{l}\text { 13. Timed } \\
\text { Walking Tests }\end{array}$ & $\begin{array}{l}\text { Scott OM, Hyde SA, Goddard } \\
\text { C, Jones R, Dubowits V. Effect } \\
\text { of exercise in Duchenne mus- } \\
\text { cular dystrophy. Physiotherapy } \\
1981 ; 67(6): 174-6^{28} \\
\text { Scott OM, Hyde SA, Goddard } \\
\text { C, Dubowitz V. Quantitation of } \\
\text { muscle function in children: a } \\
\text { prospective study in DMD. Mus- } \\
\text { cle nerve 1982;5:291-301 }{ }^{17}\end{array}$ & Tempo gasto para realizar diferentes percursos & DMD \\
\hline $\begin{array}{l}\text { 14. Function } \\
\text { evaluations }\end{array}$ & $\begin{array}{l}\text { Russman BS, Buncher CR, } \\
\text { White M et al. Function chang- } \\
\text { es in spinal muscular atrophy II } \\
\text { and III. The DCN/ SMA Group. } \\
\text { Neurology 1996;47:973-6 }{ }^{29}\end{array}$ & $\begin{array}{l}25 \text { atividades que avaliam de forma qualitativa e } \\
\text { descritiva as habilidades motoras para MMIl (sentar, } \\
\text { engatinhar, ficar de pé, andar, subir e descer escadas), } \\
\text { MMSS (elevação dos braços, flexão de antebraços e } \\
\text { flexão e extensão dos punhos) e cervicais (capacidade } \\
\text { para elevação e/ou para o sustento cervical) }\end{array}$ & $\begin{array}{l}\text { DMC com deficiência } \\
\text { da merosina }\end{array}$ \\
\hline $\begin{array}{l}\text { 15. Childhood Myosi- } \\
\text { tis Assessment Scale } \\
\text { (CMAS) }\end{array}$ & $\begin{array}{l}\text { Lovell DJ, Lindsley CB, Ren- } \\
\text { nebohm RM, et al. Develop- } \\
\text { ment of validated disease } \\
\text { activity and damage indices } \\
\text { for the juvenile idiopathic in- } \\
\text { flammatory myopathies. II } \\
\text { The Childhood Myositis As- } \\
\text { sessment Scale (CMAS): a } \\
\text { quantitative toll for the evalu- } \\
\text { ation of muscle function. The } \\
\text { Juvenile Dermatomyosistis } \\
\text { Disease Activity Collaborative } \\
\text { Study Group. Arthritis Rheum } \\
\text { 1999,42:2213-19 }{ }^{30}\end{array}$ & $\begin{array}{l}14 \text { tarefas avaliadas } \\
\text { Pontuação total (de o a 51), com a maior pontuação } \\
\text { indicando maior FM, resistência e melhor desempenho } \\
\text { na função. } \\
\text { - elevação da cabeça (flexão cervical) } \\
\text { - levantar a perna/ tocar objetos } \\
\text { - tempo que permanece com perna estendida em } \\
\text { elevação } \\
\text { - passagem de supino para prono } \\
\text { - sentar } \\
\text { - passagem de supino para sentado } \\
\text { - elevar braços estendidos } \\
\text { - tempo que permanece com braço estendido em } \\
\text { elevação } \\
\text { - sentar no chão } \\
\text { - posição em quatro apoios } \\
\text { - levantar do chão } \\
\text { - levantar da cadeira } \\
\text { - subir degraus } \\
\text { - pegar objetos }\end{array}$ & $\begin{array}{l}\text { Miopatia inflamatória } \\
\text { idiopática juvenil }\end{array}$ \\
\hline
\end{tabular}

DMD: distrofia muscular de Duchenne, DMB: distrofia muscular de Becker, AEP: amiotrofia espinhal progressiva, DFSH: distrofia fascioescapuloumeral, CMT: doença de Charcot-Marie-Tooth, DMC: distrofia muscular congênita

Quadro 3. Tabulação das escalas de funcionalidade para MMSS e AVD em relação ao nome e sigla, referência bibliográfica, componentes e doenças neuromusculares

\begin{tabular}{|c|c|c|c|}
\hline Escala & Referências Bibliográficas & Componentes & $\begin{array}{c}\text { Doenças } \\
\text { Neuromusculares }\end{array}$ \\
\hline $\begin{array}{l}\text { 1. Escala } \\
\text { de Brooke }\end{array}$ & $\begin{array}{l}\text { Brooke MH, Griggs RC, Men- } \\
\text { dell JR,Fenichel GM,Shumate } \\
\text { JB,Pellegrino RJ. Clinical trial } \\
\text { in Duchenne dystrophy: the } \\
\text { design of the protocol. Mus- } \\
\text { cle nerve } 1981 ; 4: 186-97^{4}\end{array}$ & $\begin{array}{l}\text { Paciente é classificado em um dos } 6 \text { itens: } \\
\text { 1: começando com os MMSS ao lado do corpo, paciente } \\
\text { pode abduzir os braços em uma ADM completa até alcançar } \\
\text { acima da cabeça, } \\
\text { 2: é capaz de levantar os braços acima da cabeça apenas fle- } \\
\text { xionando os cotovelos (diminuindo a amplitude de movimento) } \\
\text { ou usando músculos acessórios, } \\
\text { Se os itens } 1 \text { e } 2 \text { forem completados quantos kg podem ser } \\
\text { colocados em uma prateleira acima do nível dos olhos, com } \\
\text { uma mão?: } \\
\text { 3: não é capaz de levantar as mãos acima da cabeça mas } \\
\text { pode levantar um copo de água de } 80 z \text { até a boca (usando } \\
\text { ambas as mãos se necessário), } \\
\text { 4: é capaz de levar a mão à boca mas não é capaz de levantar } \\
\text { o copo de água de } 80 z \text { (237ml) até a boca, } \\
\text { 5: não é capaz de levar a mão à boca mas pode usar a mão para } \\
\text { segurar uma caneta ou pegar moedas em cima da mesa, } \\
\text { 6: não é capaz de levar a mão à boca, sem função manual. }\end{array}$ & $\begin{array}{l}\text { DMD, DFSH, distro- } \\
\text { fia miotônica, DMB, } \\
\text { distrofia cintura } \\
\text { membros, miopa- } \\
\text { tia congênita, CMT, } \\
\text { Ataxia de Friedrich }\end{array}$ \\
\hline
\end{tabular}


Cont. Quadro 3. Tabulação das escalas de funcionalidade para MMSS e AVD em relação ao nome e sigla, referência bibliográfica, componentes e doenças neuromusculares

\begin{tabular}{|c|c|c|c|}
\hline Escala & Referências Bibliográficas & Componentes & \begin{tabular}{|c|} 
Doenças \\
Neuromusculares \\
\end{tabular} \\
\hline $\begin{array}{l}\text { 2. Escala de } \\
\text { Vignos para MMSS }\end{array}$ & $\begin{array}{l}\text { Vignos PJ, Archibald KC, } \\
\text { Spencer G. Management of } \\
\text { progressive muscular dys- } \\
\text { trophy of childhood. JAMA } \\
1963 ; 184: 89-110^{27}\end{array}$ & $\begin{array}{l}\text { Paciente é classificado em um dos } 6 \text { itens: } \\
\text { 1: começando com os MMSS ao lado do corpo, paciente pode } \\
\text { abduzir os braços em uma ADM completa até alcançar acima } \\
\text { da cabeça.Pode colocar um peso de } 0,5 \mathrm{Kg} \text { ou mais em uma } \\
\text { prateleira acima do nível do olho. } \\
\text { 2: pode levantar os MMSS como previamente descrito mas não } \\
\text { pode colocar um peso de } 0,5 \mathrm{Kg} \text { em uma prateleira } \\
\text { 3: é capaz de levantar os braços acima da cabeça apenas fle- } \\
\text { xionando os cotovelos (diminuindo a amplitude de movimento) } \\
\text { ou usando músculos acessórios, } \\
\text { 4: não é capaz de levantar as mãos acima da cabeça mas pode } \\
\text { levantar um copo de água de } 8-0 z \text { (237ml) até a boca. } \\
\text { 5: não é capaz de levar a mão à boca mas pode usar a mão para } \\
\text { segurar uma caneta ou pegar moedas em cima da mesa, } \\
\text { 6: não é capaz de levar a mão à boca, sem função manual. }\end{array}$ & DMD; DMB \\
\hline $\begin{array}{l}\text { 3. Jebsen hand } \\
\text { function test }\end{array}$ & $\begin{array}{l}\text { Jebsen RH, Taylor N, Trie- } \\
\text { schmann RB, Trotter MJ. An } \\
\text { objective and standardized test } \\
\text { of hand function. Arch Phys } \\
\text { Med Rehabil 1969;50:311-9 }{ }^{31}\end{array}$ & $\begin{array}{l}\text { Sete atividades: escrever, virar um cartão de } 3 \times 5 \text { polegadas } \\
\text { (simulando virar uma página), pegar objetos pequenos conhe- } \\
\text { cidos, simular o ato de se alimentar, empilhar jogo de damas } \\
\text { (para avaliar coordenação fina), pegar objetos grandes e leves } \\
\text { e objetos grandes e pesados } \\
\text { Pontuação: tempo utilizado para realizar as atividades }\end{array}$ & DMD \\
\hline $\begin{array}{l}\text { 4. Functional Indepen- } \\
\text { dence Measure (FIM) }\end{array}$ & $\begin{array}{l}\text { Riberto M, Miyasaki MH, } \\
\text { Jorge DF, et al. Reproduti- } \\
\text { bilidade da versão brasileira } \\
\text { da Medida de Independência } \\
\text { Funcional. Acta fisiátrica. } \\
2001 ; 8(1): 45-52^{32}\end{array}$ & $\begin{array}{l}\text { 18 itens organizados em } 6 \text { categorias (auto-cuidado, controle esfinc- } \\
\text { teriano, transferência, locomoção, comunicação, cognição social) } \\
\text { Pontuação de cada item (de } 1 \text { a } 7 \text { ): } \\
\text { 1: total dependência } \\
\text { 2: dependência máxima } \\
\text { 3: dependência moderada supervisão, estímulo ou preparo } \\
\text { 4: dependência mínima } \\
\text { 5: supervisão } \\
\text { 6: independência modificada } \\
\text { 7: independência completa } \\
\text { Pontuação total (de } 18 \text { a 126) }\end{array}$ & DMD \\
\hline $\begin{array}{l}\text { 5. Functional Indepen- } \\
\text { dence Measure for } \\
\text { Children (WeeFIM) }\end{array}$ & $\begin{array}{l}\text { Research Foundation, State } \\
\text { University of New York: Guide } \\
\text { for the Uniform Data System } \\
\text { for Medical Rehabilitation, } \\
\text { including the Functional In- } \\
\text { dependence Measure for } \\
\text { Children (WeeFIM), version } \\
\text { 1.5. Buffalo, State University } \\
\text { of New York. } 1991^{33}\end{array}$ & $\begin{array}{l}\text { 18 itens organizados em } 6 \text { categorias (auto-cuidado, controle esfinc- } \\
\text { teriano, transferência, locomoção, comunicação, cognição social) } \\
\text { Pontuação de cada item (de } 1 \text { a } 7 \text { ): } \\
\text { 1: total dependência } \\
\text { 2: dependência máxima } \\
\text { 3: dependência moderada supervisão, estímulo ou preparo } \\
\text { 4: dependência mínima } \\
\text { 5: supervisão } \\
\text { 6: independência modificada } \\
\text { 7: independência completa } \\
\text { Pontuação total (de } 18 \text { a 126) }\end{array}$ & DMD \\
\hline $\begin{array}{l}\text { 6. Índice de Barthel } \\
\text { (IB) Mahoney, } 1965\end{array}$ & $\begin{array}{l}\text { Mahoney FI, Barthel DH. } \\
\text { Functional evaluation: the } \\
\text { Barthel Index. Md State Med } \\
\text { J 1965;14:61-5 }\end{array}$ & $\begin{array}{l}\text { Total de } 10 \text { itens: } \\
-2 \text { itens (asseio e banho), pontuação: de } 0 \text { e } 5 \\
-6 \text { itens (alimentação, evacuação, micção, vestuário, toalete, } \\
\text { escadas), pontuação: } 0,5 \text { e } 10 \\
-2 \text { itens (transferência e mobilidade), pontuação: } 0,5,10,15 \\
\text { Pontuação total (de } 0 \text { a 100) } \\
\text { 0: total dependência; } \\
\text { 100: independência máxima. }\end{array}$ & DMD \\
\hline $\begin{array}{l}\text { 7. Timed } \\
\text { Functional Tests }\end{array}$ & $\begin{array}{l}\text { Brooke MH, Fenichel GM, } \\
\text { Griggs RC, Mendell JR et al. } \\
\text { Clinical investigation in DMD: } \\
\text { 2. determination of the "pow- } \\
\text { er" of therapeutic trials based } \\
\text { on the natural history. Muscle } \\
\text { nerve } 1983 ; 6: 91-103^{13}\end{array}$ & $\begin{array}{l}7 \text { atividades: } \\
\text { 1: levantar a partir do decúbito dorsal } \\
\text { 2: subir } 4 \text { degraus (começar e terminar a atividade com os } \\
\text { braços ao longo do corpo) } \\
\text { 3: correr ou andar } 30 \text { pés ( } 9 \mathrm{~m} \text { ) (o mais rápido possível com } \\
\text { segurança) } \\
\text { 4:levantar a partir de sentado em uma cadeira (altura da ca- } \\
\text { deira deve permitir que os pés encostem no chão) } \\
\text { 5: tocar a cadeira de rodas } 30 \text { pés ( } 9 \mathrm{~m} \text { ) } \\
\text { 6: vestir uma camiseta (sentado em uma cadeira) } \\
\text { 7: cortar uma quadrado de } 3 \times 3 \text { inch ( } 8 \mathrm{~cm} \text { ) demarcado em } \\
\text { um papel com tesouras seguras (as linhas não precisam ser } \\
\text { seguidas com precisão) }\end{array}$ & DMD \\
\hline
\end{tabular}


Cont. Quadro 3. Tabulação das escalas de funcionalidade para MMSS e AVD em relação ao nome e sigla, referência bibliográfica, componentes e doenças neuromusculares

\begin{tabular}{|c|c|c|c|}
\hline Escala & Referências Bibliográficas & Componentes & $\begin{array}{c}\text { Doenças } \\
\text { Neuromusculares }\end{array}$ \\
\hline $\begin{array}{l}\text { 8. Timed } \\
\text { Functional Tests }\end{array}$ & $\begin{array}{l}\text { Jebsen RH, Taylor N, Trie- } \\
\text { schmann RB, Trotter MJ. Fas- } \\
\text { cioscapulohumeral dystrophy } \\
\text { natural history study: standard- } \\
\text { ization of testing procedures } \\
\text { and reliability of measurement. } \\
\text { Phys Ther } 1994 ; 74: 253-63^{35}\end{array}$ & $\begin{array}{l}\text { Tempo (em seg) para realização de } 3 \text { atividades: } \\
\text { - subir } 4 \text { degraus padronizados com auxílio de corrimão } \\
\text { - percorrer } 9,14 \mathrm{~m} \text { ( } 30 \text { pés) e beber } 180 \mathrm{ml} \text { ( } 6 \mathrm{fl} \text { oz) de água com } \\
\text { canudo colocado na metade dos lábios do indivíduo }\end{array}$ & DSFH \\
\hline $\begin{array}{l}\text { 9. Activies of daily } \\
\text { living (ADL) scale }\end{array}$ & $\begin{array}{l}\text { Gresham GE, Phillips TF, Labi } \\
\text { MLC. ADL status in stroke: } \\
\text { relative merits of three stan- } \\
\text { dard indexes. Arch Phys Med } \\
\text { Rehabil } 1980 ; 61: 355-8^{36}\end{array}$ & $\begin{array}{l}39 \text { itens englobando os seguintes domínios funcionais: } \\
\text { - mobilidade no leito ( } 2 \text { itens) } \\
\text { - mobilidade na CR ( } 9 \text { itens) } \\
\text { - mobilidade para deambular e ao subir escadas (6 itens) } \\
\text { - levantar e sentar ( } 5 \text { itens) } \\
\text { - auto-cuidado ( } 13 \text { itens) } \\
\text { - "miscelânea" ( } 4 \text { itens) } \\
\text { Pontuação para cada item (de } 0 \text { a 4): } \\
\text { 0: não aplicável } \\
\text { 1: independente } \\
\text { 2: realiza com mínima assistência } \\
\text { 3: precisa de assistência máxima } \\
\text { 4: totalmente dependente } \\
\text { Pontuação para cada domínio: soma da pontuação dos itens } \\
\text { deste domínio } \\
\text { Pontuação total: soma da pontuação de todos os domínios }\end{array}$ & $\begin{array}{l}\text { Distrofia muscular } \\
\text { cintura membros }\end{array}$ \\
\hline $\begin{array}{l}\text { 10. Canadian Occu- } \\
\text { pational Performance } \\
\text { Measure (COPM) }\end{array}$ & $\begin{array}{l}\text { Towsend E (ed.) (2002) En- } \\
\text { abling Occupation-An Occu- } \\
\text { pational Therapy Perspective. } \\
\text { Ottawa: Canadian Association } \\
\text { of Occupational Therapists }{ }^{37}\end{array}$ & $\begin{array}{l}\text { Características como auto-cuidado, produtividade e lazer são } \\
\text { avaliadas através de entrevista semi-estruturada } \\
\text { Pontuação de cada item (de } 1 \text { a 10) relacionada ao desem- } \\
\text { penho e satisfação: } \\
\text { 1: não é capaz de realizar/ realmente insatisfeito } \\
\text { 10:realizou extremamente bem/ extremamente satisfeito }\end{array}$ & $\begin{array}{l}\text { Distrofia } \\
\text { miotônica }\end{array}$ \\
\hline $\begin{array}{l}\text { 11. Functional Sta- } \\
\text { tus Index (FSI) }\end{array}$ & $\begin{array}{l}\text { Deniston OL, Jette A. A func- } \\
\text { tional status assessment } \\
\text { instrument: validation in an } \\
\text { elderly population. Healthy } \\
\text { Serv Res } 1980 ; 15: 21-34^{38}\end{array}$ & $\begin{array}{l}44 \text { itens relacionados as AVDs, agrupados em } 3 \text { dimensões: } \\
\text { - } 12 \text { itens sobre mobilidade } \\
\text { - } 17 \text { itens sobre cuidados pessoais } \\
\text { - } 15 \text { itens sobre trabalho } \\
\text { Para cada atividade são feitas } 3 \text { questões sobre dependência, } \\
\text { dificuldade e dor } \\
\text { Pontuação total ( } 0 \text { a } 176) \\
\text { Pontuação para cada dimensão: } \\
\text { - mobilidade (de } 0 \text { a } 48 \text { ) } \\
\text { - cuidados pessoais (de } 0 \text { a } 68) \\
\text { - trabalho (de } 0 \text { a } 60 \text { ) } \\
\text { Pontuação para cada item (de } 0 \text { a 4) } \\
\text { 0: independente } \\
\text { 1: uso auxílio mecânico } \\
\text { 2: usa auxílio humano } \\
\text { 3: usa ambos os tipos de auxílio } \\
\text { 4: não realiza a atividade }\end{array}$ & $\begin{array}{l}\text { Distrofia } \\
\text { miotônica }\end{array}$ \\
\hline $\begin{array}{l}\text { 12. Timed Function- } \\
\text { al Tasks (TFT) }\end{array}$ & $\begin{array}{l}\text { Appel V, Stewart SS, Smith } \\
\text { G, et al. A rating scale for } \\
\text { lateral amyotrophic sclero- } \\
\text { sis: description and prelimi- } \\
\text { nary experience. Ann Neurol } \\
\text { 1987;22:328-33 }{ }^{39}\end{array}$ & $\begin{array}{l}\text { Tempo (em seg) para realização de: } \\
\text { Atividades para extremidade inferior: } \\
\text { - levantar a partir de posição sentada em uma cadeira } \\
\text { - levantar a partir da posição em supino } \\
\text { - andar } 20 \text { pés com auxiliares de marcha, se necessário } \\
\text { - subir e descer quatro degraus com auxiliares de marcha, } \\
\text { se necessário } \\
\text { Tarefas para extremidade superior: } \\
\text { - empurrar uma cadeira de rodas num percurso de } 20 \text { pés } \\
\text { - cortar um pedaço de theraplast espesso de } 1 / 4 \text { polegada com } \\
\text { uma faca plástica posicionada na mão dominante durante } 0 \\
\text { início da tarefa } \\
\text { - reunir pregadores e colocá-los no varal_durante } 60 \text { segundos } \\
\text { - usando uma mão de cada vez, virar blocos } 21 / 2 \text { polegadas } \\
\text { de diâmetro e } 3 / 4 \text { polegadas de altura em uma mesa durante } \\
60 \text { segundos }\end{array}$ & $\begin{array}{l}\text { Distrofia } \\
\text { miotônica }\end{array}$ \\
\hline
\end{tabular}

DMD: distrofia muscular de Duchenne, DMB: distrofia muscular de Becker, DFSH: distrofia fascioescapuloumeral, CMT: doença de Charcot-Marie-Tooth 
Quadro 4. Tabulação das escalas de qualidade de vida em relação ao nome e sigla, referência bibliográfica, componentes e doenças neuromusculares

\begin{tabular}{|c|c|c|c|}
\hline Escala & $\begin{array}{c}\text { Referências } \\
\text { Bibliográficas }\end{array}$ & Componentes & $\begin{array}{c}\text { Doenças } \\
\text { Neuromusculares } \\
\end{array}$ \\
\hline $\begin{array}{l}\text { 1. Short Form - } 36 \text { Health } \\
\text { Survey (SF-36) }\end{array}$ & $\begin{array}{l}\text { Ware JE, Sherbourne CD. } \\
\text { The MOS 36-item short } \\
\text { form health survey (SF- } \\
\text { 36): I Conceptual frame } \\
\text { work and item. Med Care } \\
\text { 1992;30:473-83 } 40\end{array}$ & $\begin{array}{l}\text { Instrumento de auto avaliação organizado em } 8 \text { dimensões: } \\
\text { - funcionalidade ( } 10 \text { itens), } \\
\text { - limitação ocasionada pelo problema físico ( } 4 \text { itens), } \\
\text { - dor corporal ( } 2 \text { itens), } \\
\text { - percepção geral da saúde ( } 5 \text { itens), } \\
\text { - vitalidade ( } 4 \text { itens), } \\
\text { - função social ( } 2 \text { itens), } \\
\text { - limitação ocasionada pelo problema emocional ( } 3 \text { itens), } \\
\text { - saúde mental ( } 5 \text { itens) } \\
\text { A pontuação é obtida através de um algoritmo (de } 0 \text { a 100): } \\
0 \text { : menor qualidade de vida } \\
\text { 100: maior qualidade de vida }\end{array}$ & $\begin{array}{l}\text { Miopatias, distrofia } \\
\text { miotônica, distrofia } \\
\text { muscular proximal, } \\
\text { distrofia muscular } \\
\text { distal, miopatia in- } \\
\text { flamatória idiopática } \\
\text { do adulto }\end{array}$ \\
\hline $\begin{array}{l}\text { 2. Sickness Impact } \\
\text { Profile (SIP) }\end{array}$ & $\begin{array}{l}\text { Bergner M, Bobitt, RA, } \\
\text { Carter WB. The Sick- } \\
\text { ness Impact Profile: } \\
\text { development and final } \\
\text { revision of health sta- } \\
\text { tus measure. Med Care } \\
\text { 1981; 19:787-805 }{ }^{41}\end{array}$ & $\begin{array}{l}136 \text { situações da vida diárias separadas em } 12 \text { categorias } \\
\text { (sono e descanso, alimentação, cuidados com a casa, recrea- } \\
\text { ção e lazer, cuidados com o corpo e movimento, deambulação, } \\
\text { mobilidade, comportamento afetivo e emocional, interação } \\
\text { social, comunicação e trabalho) } \\
\text { Pontuação da dimensão física (cuidado com o corpo e movi- } \\
\text { mento, deambulação e mobilidade) } \\
\text { Pontuação da dimensão psicossocial (comportamento emo- } \\
\text { cional e afetivo, interação social e comunicação) } \\
\text { Pontuação total (soma das } 12 \text { categorias) (de } 0 \text { a 100\%) } \\
\text { Quanto maior a pontuação, mais séria a disfunção, pontuação } \\
>10 \% \text { indica desvantagem clínica. }\end{array}$ & $\begin{array}{l}\text { Doenças } \\
\text { neuromusculares }\end{array}$ \\
\hline 3. Health Index $(\mathrm{HI})$ & $\begin{array}{l}\text { Langius A, Bjorvell } H, \\
\text { Lind M. Oral-and pha- } \\
\text { ryngeal- cancer patients } \\
\text { perceived symptoms and } \\
\text { health. Cancer Nurse } \\
\text { 1993;16:214-21 } 42\end{array}$ & $\begin{array}{l}11 \text { itens (fadiga, energia, sono, mobilidade, humor, solidão, } \\
\text { função gastrointestinal, vertigem, dor, saúde durante a última } \\
\text { semana, saúde geral) } \\
\text { Pontuação para cada item (de } 1 \text { a 4); } \\
\text { 1: muito pobre } \\
\text { 2: pobre } \\
\text { 3: bom } \\
\text { 4: muito bom } \\
\text { Nove itens somam a pontuação de } 9 \text { a } 36 \\
\text { Dois últimos itens são calculados como um único item } \\
\text { Quanto maior a pontuação, melhor a percepção de saúde }\end{array}$ & $\begin{array}{l}\text { Doenças } \\
\text { neuromusculares }\end{array}$ \\
\hline $\begin{array}{l}\text { 4. Sense of Coherence } \\
\text { Scale (SCO) }\end{array}$ & $\begin{array}{l}\text { Antonovsky A. The } \\
\text { structure and properties } \\
\text { of the sense of coher- } \\
\text { ence scale. Soc Sci Med } \\
1993 ; 36: 725-33^{43}\end{array}$ & $\begin{array}{l}\text { Mede a compreensão, o controle e o significado das situações } \\
\text { de stress na vida } \\
13 \text { itens são somados para gerar uma pontuação total (de } 13 \text { a 91) } \\
\text { Quanto maior a pontuação mais forte o senso de coerência e } \\
\text { melhor a percepção de saúde }\end{array}$ & $\begin{array}{l}\text { Doenças } \\
\text { neuromusculares }\end{array}$ \\
\hline $\begin{array}{l}\text { 5. Life Domain Satisfac- } \\
\text { tion Measures }\end{array}$ & $\begin{array}{l}\text { Campbell A, Converse } \\
\text { PE, Rodgers WL. The } \\
\text { Quality of American Life: } \\
\text { Perceptions, Evaluations } \\
\text { and Satisfactions. New } \\
\text { York, Russell Sage Foun- } \\
\text { dation 1976. p. } 37-113^{44} \\
\end{array}$ & $\begin{array}{l}\text { Avaliação pessoal quanto à satisfação nos dimensões: traba- } \\
\text { Iho doméstico, transporte, educação, trabalho, saúde, vida } \\
\text { social, vida sexual, vida em geral } \\
\text { Pontuação de cada domínio (de } 1 \text { a } 7 \text { ) : } \\
\text { 1: completamente insatisfeito } \\
\text { 7: completamente satisfeito }\end{array}$ & DMD \\
\hline $\begin{array}{l}\text { 6. Semantic Differential } \\
\text { Scale of General Affect }\end{array}$ & $\begin{array}{l}\text { Campbell A, Converse } \\
\text { PE, Rodgers WL. The } \\
\text { Quality of American Life: } \\
\text { Perceptions, Evaluations } \\
\text { and Satisfactions. New } \\
\text { York, Russell Sage Foun- } \\
\text { dation 1976. p. } 37-113^{44}\end{array}$ & $\begin{array}{l}\text { Avaliação quanto à satisfação com a vida, contendo } 8 \text { domí- } \\
\text { nios, caracterizados através de adjetivos opostos, colocados } \\
\text { nos extremos de uma escala de } 7 \text { pontos } \\
\text { - Sem graça - interessante } \\
\text { - Miserável - agradável } \\
\text { - Difícil - fácil } \\
\text { - Inútil- recompensador } \\
\text { - Solitária- amigável } \\
\text { - Vazia - completa } \\
\text { - Sem esperança - esperançosa } \\
\text { - Sufocante- livre } \\
\text { - Desapontadora - recompensadora } \\
\text { - Sem chance - o melhor de mim }\end{array}$ & DMD \\
\hline
\end{tabular}


Quadro 5: Tabulação das escalas de diferentes domínios em relação ao nome e sigla, referência bibliográfica, domínios, componentes e doenças neuromusculares

\begin{tabular}{|c|c|c|c|c|}
\hline Escala & $\begin{array}{l}\text { Referências } \\
\text { Bibliográficas }\end{array}$ & Domínios & Componentes & $\begin{array}{l}\text { Doenças } \\
\text { Neuromusculares }\end{array}$ \\
\hline $\begin{array}{l}\text { 1. Egen Klassifi- } \\
\text { cation (EK) }\end{array}$ & $\begin{array}{l}\text { Steffensen BF, Hyde S, Ly- } \\
\text { ager S, Mattson E. Validity of } \\
\text { the EK scale: a functional as- } \\
\text { sessment of non-ambulatory } \\
\text { individuals with Duchenne } \\
\text { muscular dystrophy or spinal } \\
\text { muscular atrophy. Phys Res } \\
\text { Int } 2001 ; 6(3): 119-344^{45}\end{array}$ & $\begin{array}{l}\text { AVD } \\
\text { Comunicação } \\
\text { Eficácia da tosse } \\
\text { Bem-estar }\end{array}$ & $\begin{array}{l}10 \text { categorias verificando as habilidades em: } \\
\text { - usar cadeira de rodas (CR), } \\
\text { - se transferir da CR, } \\
\text { - permanecer em pé, } \\
\text { - manter o equilíbrio na CR, } \\
\text { - mover os MMSS, } \\
\text { - usar mãos e MMSS durante alimentação, } \\
\text { - se virar na cama, } \\
\text { - tossir, } \\
\text { - falar; } \\
\text { - e o bem-estar físico. } \\
\text { Pontuação em cada categoria (de } 0 \text { a 3): } \\
\text { 0: melhor desempenho na tarefa e sem queixas } \\
\text { quanto ao bem-estar físico } \\
\text { 3: pior desempenho na tarefa e com sintomas } \\
\text { de mal estar físico } \\
\text { Pontuação total (de } 0 \text { a 30): } \\
\text { 0: maior nível de independência funcional; } \\
\text { 30: menor nível de independência funcional. }\end{array}$ & DMD, AEP \\
\hline $\begin{array}{l}\text { 2. Griffiths' } \\
\text { Mental De- } \\
\text { velopmental } \\
\text { Scales (GMDS) }\end{array}$ & $\begin{array}{l}\text { Hanson R, Albridge-Smith } \\
\text { D, Hume W. Achivements } \\
\text { on items of the Griffiths } \\
\text { Scales: } 1980 \text { compared } \\
\text { with } 1950 \text {. Child care health } \\
\text { dev.11:91-104 }{ }^{23}\end{array}$ & $\begin{array}{l}\text { Mobilidade } \\
\text { Integração social } \\
\text { Comunicação } \\
\text { Coordenação } \\
\text { olho-mão } \\
\text { Raciocínio }\end{array}$ & $\begin{array}{l}\text { As pontuações dos domínios foram citadas na } \\
\text { referência. }\end{array}$ & DMD \\
\hline $\begin{array}{l}\text { 3. Total Functio- } \\
\text { nal Grade (TFG) }\end{array}$ & $\begin{array}{l}\text { Nair KPS, Vasanth A, Gou- } \\
\text { rie-Devi M, Taly AB. et al. } \\
\text { Disabilities in children with } \\
\text { DMD: a profile. J Rehabil } \\
\text { Med } 2001 ; 33: 147-9^{14}\end{array}$ & $\begin{array}{l}\text { Mobilidade } \\
\text { Funcionalidade } \\
\text { MMSS }\end{array}$ & $\begin{array}{l}\text { Soma dos valores de Vignos e Brooke para cada } \\
\text { paciente (pontuação de } 2 \text { a 16): } \\
\text { 2: normal } \\
\text { 16: confinado ao leito/ sem função manual }\end{array}$ & DMD \\
\hline $\begin{array}{l}\text { 4. Physical } \\
\text { index }\end{array}$ & $\begin{array}{l}\text { Smits SJ. Variables related to } \\
\text { success in medical rehabili- } \\
\text { tation setting. Arch Phys Med } \\
\text { Rehabil 1974;55:449-5446 }\end{array}$ & $\begin{array}{l}\text { Mobilidade } \\
\text { Auto-cuidado }\end{array}$ & $\begin{array}{l}\text { Mobilidade: escala de } 10 \text { itens } \\
\text { Pontuação (de } 0 \text { a 10) } \\
\text { 0: não deambula e não faz uso de CR, é acamado } \\
\text { 10: sem restrições para marcha em ambiente } \\
\text { interno e externo } \\
\text { Auto-cuidado: escala de } 4 \text { itens (alimentação, } \\
\text { vestuário, higiene pessoal e banho) } \\
\text { Pontuação (de } 0 \text { a 10) } \\
\text { 0: não realiza nenhuma das atividades de forma } \\
\text { independente } \\
\text { 10: realiza todas as atividades de forma inde- } \\
\text { pendente }\end{array}$ & Distrofias e ataxias \\
\hline $\begin{array}{l}\text { 5. Stanford } \\
\text { Health Assess- } \\
\text { ment Question- } \\
\text { aire (HAQ) }\end{array}$ & $\begin{array}{l}\text { Sultan SM. Clinical assess- } \\
\text { ment in adult onset idio- } \\
\text { pathic inflammatory myop- } \\
\text { athy. Curr Opin Rheumatol } \\
2004 ; 16: 668-72^{16}\end{array}$ & $\begin{array}{l}\text { AVD } \\
\text { Dor } \\
\text { Fadiga } \\
\text { Sono }\end{array}$ & $\begin{array}{l}\text { Composto por } 8 \text { domínios (vestuário, levantar, } \\
\text { comer, andar, higiene, alcançar, preensão, ati- } \\
\text { vidades sociais) } \\
\text { Inclui avaliação de dor, severidade global, fadiga, } \\
\text { escala visual análoga sobre sono }\end{array}$ & $\begin{array}{l}\text { Miopatia inflamató- } \\
\text { ria do adulto }\end{array}$ \\
\hline
\end{tabular}

DMD: distrofia muscular de Duchenne, AEP: amiotrofia espinhal progressiva, AVD: atividades de vida diária, MMSS: funcionalidade para membros superiores, $\mathbf{C R}$ : cadeira de rodas.

doenças neuromusculares (DNM) e em outras doenças do sistema nervoso. O grau de confiabilidade depende dos grupos musculares testados e do grau de força pontuado. No entanto, existem inconsistências inter e intra observadores e falta de sensibilidade, mas estes aspectos não têm impedido sua ampla utilização ${ }^{48}$. Se os graus de força são utilizados para decisões clínicas, recomenda-se que a confiabilidade seja documentada entre os vários métodos de testes de força manual, faixas etárias e populações de pacientes ${ }^{47}$.
Entre os 12 instrumentos encontrados, a escala do MRC foi a mais citada entre os estudos analisados, sendo esta sugerida como a mais adequada para um estudo multicêntrico, apesar de algumas desvantagens, como as citadas anteriormente. Tal escala foi modificada por alguns autores para que se adaptasse melhor às características dos diferentes pacientes. A forma original de graduação da força contém apenas 6 níveis, o que não permite estabelecer diferença com características diversas. Um exemplo disso é a categoria designada como "4" na escala de MRC ("O 
músculo move a articulação contra a gravidade e alguma resistência") que é ampla; um músculo permanece nesta categoria desde o primeiro sinal de fraqueza até o músculo ser tão fraco para mover a articulação contra a gravidade . Dessa forma, variações na pontuação tornaram-se comuns sem qualquer base real objetiva. Além disso, não se encontrou um estudo que avaliasse a validade ou sensibilidade da escala do MRC e suas modificações em documentar mudanças ao longo do tempo ou, quantificar se era sensível ou aplicável na comparação com outros métodos de avaliação de força e desempenho muscular ${ }^{47}$.

Em alguns dos estudos ${ }^{12-17}$ em questão, a força mensurada na escala do MRC em músculos isolados foi convertida em equações, que unificavam grupos musculares em uma pontuação total, de acordo com os músculos de interesse para cada autor. Em um estudo com pacientes com DMD encontrou-se a melhor concordância, quando graus de força para grupos musculares específicos foram combinados em uma pontuação total. Tal achado sugere que a medida mais estável para documentação da força em doenças ou intervenções sistêmicas é uma pontuação composta ${ }^{47}$.

O teste de força muscular tem sido criticado como sendo altamente subjetivo, sujeito a erros, por não ser uma medida quantitativa confiável sobre o progresso de qualquer DNM. Instrumentos mecânicos, como dinamômetros também têm sido utilizados para obter dados quantitativos de força. Estes aparelhos, embora confiáveis quando utilizados por examinadores experientes são de difícil padronização e possuem um custo considerável. Por variarem de design e sensibilidade, nenhum deles conseguiu, até então atingir grande popularidade ${ }^{49}$.

Sendo assim, apesar da força muscular ser uma capacidade condicionante muito alterada nas miopatias e, portanto, imprescindível avaliá-la para o acompanhamento da evolução da doença, ainda é controverso na literatura qual o sistema de medida é o ideal para ser utilizado nestes casos.

\section{Avaliação da dor}

Dor é um sintoma que a maioria dos profissionais de saúde não associa à DNM. Muitos dos estudos em miopatias não citam este sintoma. No entanto, foi encontrado um artigo científico que indica que a dor é um problema comum na maioria dos pacientes com $\mathrm{DNM}^{19}$. Pouco se sabe sobre a natureza, âmbito, áreas do corpo a que se associam e, tratamento da dor nestes pacientes. No estudo em questão ${ }^{19}$, foram analisadas: a intensidade, qualidade e localização da dor, além da interferência da dor na funcionalidade e na qualidade de vida destes pacientes ${ }^{19}$.

Quanto à intensidade da dor, apesar da escala Graded Chronic Pain Scale (Von Korff ) ser subjetiva, ela apresentou boa confiabilidade em detectar mudanças ao longo do tempo. A Neuropathic Pain Scale possibilitou diferenciar pacientes com diagnósticos diversos e sua responsividade ao tratamento quanto à mensu- ração dos aspectos qualitativos da dor. A escala Brief Pain Inventory mostrou excelente consistência interna e validade em uma amostra de pacientes com paralisia cerebral. Estes aspectos, no entanto, ainda não foram testados em pacientes com DNM.

Convém destacar que se verificou ser a dor um problema comum e significante para muitos pacientes com $\mathrm{DNM}^{19}$, contudo o impacto deste sintoma não tem sido amplamente pesquisado.

\section{Avaliação do equilíbrio}

Devido à alteração biomecânica ocasionada pela fraqueza muscular, as reações de equilíbrio, proteção e retificação estarão prejudicadas. Por esta razão é que muitas vezes, têm-se como queixa principal quedas freqüentes. Inicialmente são reações que podem ser lentificadas e, posteriormente podem estar ausentes devido ao caráter progressivo das DNM ${ }^{50}$.

A escala de equilíbrio de Berg foi o único instrumento referente ao equilíbrio, nos estudos analisados. Possui boa objetividade de teste-reteste e já foi validada na língua portuguesa. Assim, como a maioria das medidas funcionais, o teste de equilíbrio de Berg apresenta limitações, fornece poucas informações sobre a qualidade do movimento utilizado para executar a tarefa ${ }^{51}$.

Sendo assim, escalas mais sensíveis podem apontar mudanças ao longo de toda a evolução das miopatias e, não apenas em alguns períodos críticos de mudança do ajuste postural, podendo colaborar com o acompanhamento mais detalhado e significativo destas doenças, permitindo uma intervenção mais efetiva.

\section{Avaliação da mobilidade e/ou locomoção}

Perdas relacionadas à mobilidade e locomoção resultam em importantes alterações na independência funcional. Os pacientes valorizam mais rapidamente melhora na função do que, por exemplo, na força muscular. A análise da função motora é essencial ao avaliar doenças musculares, especialmente para interpretação objetiva do impacto no indivíduo. A avaliação funcional é facilmente padronizada e confiável, podendo ser realizada, com pequeno ou nenhum custo, na maioria dos serviços. O desafio primário para pesquisadores que desejam incorporar testes funcionais é identificar os instrumentos que melhor mensuram a história natural das doenças específicas sob investigação ${ }^{52}$.

O método ideal para documentar a evolução da doença neuromuscular deve ser barato, fácil de ser utilizado em ambiente clínico e reprodutível. Testes funcionais alcançam de forma significativa tais objetivos. Uma limitação importante dos testes funcionais é que estes, não são sensíveis para todos os estágios da doença. Outras limitações incluem a falta de sensibilidade para detectar um aumento ou declínio súbito na força muscular e a dificuldade em aplicar métodos estatísticos padronizados para analisar a progressão da doença ou eficácia terapêutica ${ }^{52}$. 
Neste estudo foram encontradas 11 escalas de mobilidade e locomoção, sendo que uma delas estava relacionada aos marcos de progressão da doença, três estudos incluíram testes funcionais cronometrados e, seis englobaram pontuações compostas de diferentes funções.

A escala de Vignos, que caracteriza o indivíduo de acordo com os marcos de evolução da doença, tornouse o "padrão ouro" na avaliação da habilidade funcional em casos de DMD, este fato foi confirmado pela grande quantidade de artigos científicos encontrados que o utilizaram como instrumento de avaliação. Este tem sido amplamente utilizado porque consiste em um método simples e preciso para analisar o desempenho muscular global ${ }^{22}$, apesar de apresentar pouca especificidade.

Os testes cronometrados têm sido utilizados na prática clínica como uma forma de avaliação da progressão. As mensurações geralmente utilizadas incluem levantar a partir do chão (sinal de Gowers) e, tempo para correr uma determinada distância e tempo para subir escadas ${ }^{53}$, mas não houve critérios de padronização entre os diferentes autores quanto estas atividades.

A mensuração funcional motora (MFM) é uma escala confiável, recentemente validada, que não requer nenhum equipamento especial, e é bem aceita pelos pacientes. Além dela, há outras que também avaliam a gravidade e progressão das DNM e compõe o grupo de pontuações compostas de diferentes funções ${ }^{25}$.

A avaliação funcional é imprescindível para pacientes com doença neurológica e, deve ser utilizada de rotina na prática clínica e, também em pesquisas a fim de traduzir os efeitos da doença e suas conseqüências nas atividades do indivíduo, aspecto de maior relevância para a maioria deles.

\section{Avaliação da funcionalidade de membros superio- res (MMSS)}

Quando se propõem programas terapêuticos em fisioterapia, a identificação de problemas específicos a serem abordados, bem como a quantificação dos progressos dos pacientes e o estabelecimento de novas prioridades devem ser documentados de maneira compreensível e reprodutível ${ }^{32}$.

Tendo em vista a funcionalidade de MMSS, foram encontrados 3 instrumentos: escalas de Brooke, Vignos para MMSS e Jebsen.

As escalas de Brooke e Vignos para MMSS, quando comparadas, possuem apenas discretas diferenças em relação aos itens analisados. A escala de Brooke não acompanha adequadamente a progressão da doença na $\mathrm{DMD}$ no que se refere à função manual ${ }^{54}$. Convém destacar que a sensibilidade da escala de Vignos para MMSS não foi verificada nos estudos analisados.

Ao comparar os resultados das escalas de Jebsen e Brooke, uma consideração importante é que a primeira solicita que todos os pacientes usem os mesmos grupos musculares para todas as tarefas, enquanto que a escala de Brooke testa diferentes grupos musculares para cada um dos 6 níveis ${ }^{54}$.

Utilizar uma escala que mensura o tempo para realização das atividades, como a de Jebsen, ao invés de uma escala ordinal simples com 6 categorias como a de Brooke, determina uma medida mais discriminativa de função manual, o que fornece um método mais sensível de acompanhar a história natural da doença e o progresso do paciente quando, por exemplo, ocorrer o início de determinada intervenção terapêutica ${ }^{54}$.

A grande variabilidade nas pontuações da escala de Jebsen, relacionada a uma mesma categoria da escala de Brooke sugere que os pacientes com DMD, que foram pontuados com a mesma graduação funcional de Brooke devem, na realidade, apresentar diferentes graus de habilidades funcionais. Uma ampla variedade nas pontuações do teste de Jebsen indica significante habilidade discriminativa do teste ${ }^{54}$.

A avaliação funcional dos membros superiores é de suma importância, em especial para os terapeutas ocupacionais.

\section{Avaliação das atividades de vida diária (AVDs)}

O objetivo primário de qualquer avaliação em pacientes com doenças crônicas é otimizar a função na vida diária e, no caso das DNM prolongar ao máximo sua independência funcional ${ }^{55}$. Uma escala de AVDs avalia a incapacidade em diversos domínios funcionais a partir do auto-relato dos pacientes ${ }^{56}$.

A caracterização das AVDs, realizado pelos 9 instrumentos mencionados neste estudo pode fornecer parâmetros úteis para acompanhamento clínico de doenças progressivas, quando testes musculares manuais tornam-se insuficientemente sensíveis para detectar a deterioração clínica ${ }^{48}$. Para suprir esta perda são necessárias, então, diferentes tipos de avaliações para auxiliar nas atividades a serem analisadas.

As escalas de avaliação das AVDs encontradas incluíam pontuações ou testes cronometrados de atividades relacionadas à higiene, vestuário, conduzir cadeira de rodas, alimentação, entre outros. Os diferentes tipos de mensuração se adaptavam mais adequadamente aos pacientes analisados, segundo cada autor. No entanto, ainda não foi estabelecido um consenso sobre qual a melhor escala a ser utilizada.

\section{Avaliação da qualidade de vida}

Qualidade de vida foi definida como a percepção do indivíduo a partir de sua posição no contexto dos sistemas culturais e de valores em que se vive e em relação aos seus objetivos, expectativas, padrões e conceitos. É um conceito amplo, que incorpora uma visão complexa da saúde física, estado psicológico, nível de independência, relacionamentos sociais, crenças pessoais e suas relações com características importantes do ambiente. Esta definição mostra que 
a visão de qualidade de vida é subjetiva, inclui tanto aspectos positivos quanto negativos da vida e, é multidimensional. No mínimo, inclui as dimensões seguintes: física (percepção do indivíduo sobre seu próprio estado de saúde), psicológica (percepção do indivíduo sobre o estado cognitivo), afetivo e social (percepção do indivíduo sobre suas relações inter-pessoais e funções sociais em sua vida) ${ }^{57}$.

Devido ao interesse por esses instrumentos, ainda que sejam consideradas avaliações holísticas de abordagem baseada na avaliação de escalas de mensuração, tem sido cada vez mais utilizada, especialmente quando nenhuma referência ou "padrão ouro" de mensuração satisfatória está disponível ${ }^{58}$. Embora se conheça intuitivamente o impacto das diferentes condições crônicas na funcionalidade e bem-estar, tornam-se necessárias mensurações precisas e práticas destas variáveis ${ }^{55} \mathrm{em}$ pacientes com doenças neuromusculares.

Nessa revisão foram encontrados 6 instrumentos que objetivam avaliar a qualidade de vida. Dentre estes, o mais citado foi o SF-36 (Medical Outcomes Study 36 - Item Short Form Health Survey), uma medida de autoavaliação do status funcional que consiste em mensurar a saúde e a extensão em que ela é afetada pela doença, do ponto de vista do paciente, por meio da pontuação de respostas às perguntas padronizadas sobre atividades diárias e função ${ }^{59}$. No entanto, esta escala parece ser inadequada para pacientes que não deambulam, como os miopatas, interferindo no escore do domínio físico deste instrumento. Esta escala de avaliação já foi traduzida para o português e adequada às condições sócio-econômicas e culturais de nossa população, bem como demonstrada sua reprodutibilidade e validade ${ }^{60}$. Assim como a SF-36, as demais escalas encontradas avaliaram tanto aspectos físicos, quanto psicossociais e não foram desenvolvidas especificamente para miopatias. Isso, não restringiu sua utilização em diferentes estudos, mas a elaboração de um instrumento específico de qualidade de vida para doenças musculares faz-se necessário.

\section{Avaliação de outros aspectos}

Para avaliação completa dos benefícios de uma intervenção é necessário fornecer evidências sobre o impacto, sob a perspectiva do paciente em termos de estado de saúde e qualidade de vida, ou seja, experiências como dor, fadiga e incapacidade relacionadas à doença, além de aspectos mais amplos do bem-estar físico, emocional, e social do indivíduo. Ao contrário dos indicadores clínicos, estes aspectos mais amplos da doença e do tratamento devem, sempre que possível, ser avaliados e relatados pelo paciente ${ }^{61}$.

Tendo em vista a avaliação de diferentes domínios, cinco instrumentos foram encontrados neste estudo em questão, verificando-se que a escala Egen Klassifikation (EK) foi recentemente elaborada. É uma mensuração composta que avalia diferentes domínios da função, desenvolvida para avaliar habilidades funcionais presentes em pacientes nos estágios avançados da DMD desde o período em que ocorre a perda da marcha independente sem uso de órteses longas, até a perda completa da função. Apresenta alta confiabilidade inter e intra observadores entre indivíduos com DMD quando utilizada por fisioterapeutas com diferentes níveis de experiência e por outros profissionais da área de saúde ${ }^{62}$.

\section{Avaliação da amplitude de movimento (ADM)}

No caso de indivíduos com miopatias devido, principalmente ao desequilíbrio muscular e, conseqüente limitação física torna-se necessário uma padronização para quantificar a ADM.

Um método de avaliação cada vez mais utilizado neste século e, principalmente nas últimas décadas é a goniometria. Esse método é usado pelo fisioterapeuta para quantificar a amplitude de movimentos articulares, decidir a intervenção terapêutica mais apropriada e, ainda documentar a efetividade dessa intervenção. É, provavelmente um dos procedimentos mais utilizados na avaliação fisioterapêutica, podendo ser considerado como parte funcional da ciência da fisioterapia ${ }^{63,64}$.

Apresenta algumas vantagens: fácil manuseio, baixo custo e rápida execução ${ }^{63}$. No entanto, a execução deste método de avaliação não foi, nos diversos estudos encontrados, descrita com clareza. Não houve consenso em relação à forma de mensuração dos graus de amplitude, e os valores de referência usados para as diferentes articulações, dificultando a análise das variações do uso deste instrumento 3,4, 13, 17,28,53, 65-70

A identificação e caracterização de instrumentos de avaliação na área da neurologia podem facilitar tanto a ação dos profissionais que prestam assistência, como os projetos de pesquisadores que estudam os efeitos das diversos intervenções terapêuticas pois, estes podem mais rapidamente eleger os instrumentos necessários para averiguar o tratamento e estudar os casos ${ }^{71}$.

\section{CONCLUSÃO}

Foram encontrados 49 instrumentos de avaliação para pacientes com miopatia que englobaram os itens: força muscular, dor, equilíbrio, mobilidade e/ou locomoção, funcionalidade, atividades de vida diária, qualidade de vida e outros aspectos (eficácia da tosse, bem-estar, integração social, comunicação, coordenação olho-mão, raciocínio, auto-cuidado, fadiga e sono). Destas, apenas duas foram traduzidas para língua portuguesa e, poucas foram elaboradas especificamente para pacientes com doenças neuromusculares. Sendo assim, tornam-se necessários estudos de tradução e validação destes instrumentos para a língua portuguesa falada no Brasil e, elaboração de escalas que permitam avaliar e acompanhar o paciente ao longo da evolução da doença. 


\section{REFERÊNCIAS BIBLIOGRÁFICAS}

1. Reed UC. Miopatias. In: Diament A. Neurologia infantil; $3^{\mathrm{a} e d .}$ São Paulo: Atheneu, 1996, p 1103-27.

2. Cunha MCB. Efeitos da oxandrolona (esteróide anabólico androgênico) e dos exercícios aquáticos no tratamento de pacientes com doença neuromuscular tese. São Paulo: Universidade Federal de São Paulo - UNIFESP, 2004.

3. Barr AE, Diamond BE, Wade CK, Harashima T, Pecorella WA, Potts CC et al Reliability of testing measures in Duchenne or Becker muscular dystrophy. Arch Phys Med Rehabil 1991; 72:315-319.

4. BrookeMH, GriggsRC, Mendell JR, Fenichel GM, Shumate JB, Pellegrino RJ. Clinical trial in Duchenne dystrophy: the design of the protocol. Muscle nerve 1981;4:186-197.

5. Battistela LR, Brito CMM. Classificação Internacional de Funcionalidade (CIF). Acta Fisiatr 2002;9:98-101.

6. Ferguson BM, Keown MB. An introduction to utility measurement in health care. Infec Control Hosp Epidemiol. 1995;16:240-247.

7. Medical Research Council. Aids to the Investigation of Peripheral Nerve Injuries. War Memorandum (revised 2nd edition). London: HMSO, 1943.

8. Daniels L, Worthingham C. Muscle testing: techniques of manual examination. 5thed. Philadelphia, PA: WB Saunders Co, 1986.

9. Kendall FP, McCreary EK, Provance PG. Muscles: testing and function 4th ed. Baltimore: Williams \& Wilkins, 1993.

10. Bakker JPJ, de Groot IJM, Beelen A, Lankhorst GJ. Predictive factors of cessation of ambulation in patients with DMD. Am J Phys Med Rehabil 2002;81:906-912.

11. Mathieu J, de Braekeleer MD, Prévost C, Boily C. Myotonic dystrophy: clinical assessment of muscular disability in na isolated population with presumed homogeneous mutation. Neurology 1992;42:203-208.

12. Mathieu J, Boivin H, Meunier D, Gaundreault M, Bégin P. Assessment of a disease-specific muscular impairment rating scale in myotonic dystrophy. Neurology 2001;56:336-340.

13. Brooke MH, Fenichel GM, Griggs RC, Mendell JR, Moxley R, Miller JP, et al Clinical investigation in DMD: 2. determination of the "power" of therapeutic trials based on the natural history. Muscle nerve 1983;6:91-103.

14. Nair KPS, Vasanth A, Gourie-Devi M, Taly AB, Rao S, Gayathri N, et al. Disabilities in children with DMD: a profile. J Rehabil Med 2001:33:147-149.

15. Florence JM, Pandya S, King WM, Robison JD, Signore LC, Wentzell M, et al.Clinical trials in Duchenne dystrophy. Standardization and reliability of evaluation procedures. Phys Ther 1984;64(1):41-45.

16. Sultan SM. Cinical assessment in adult onset idiopathic inflammatory myopathy. Curr Opin Rheumatol 2004;16:668-672.

17. Scott OM, Hyde SA, Goddard C, Dubowitz V. Quantitation of muscle function in children: a prospective study in DMD. Muscle nerve 1982:5:291-301.

18. Von Korff M, Ormel J, Keefe FJ. Grading the severity of chronic pain. Pain 1992; 50:133-149

19. Jensen MP, Abresch RT, Carter GT, McDonald CM. Chronic pain in persons with neuromuscular disease. Arch Phys Med Rehabil 2005;86:1155-1163.
20. Tyler EJ, Jensen MP, Engel JM. The reliability and validity of pain interference measures in persons with cerebral palsy. Arch Phys Med Rehabil 2002;83:236-239.

21. Miyamoto ST, Junior IL, Berg KO, Ramos LR, Natour JZ. Brazilian version of the Berg Balance Scale. J Med Biol Res 2004;37(9):1411-1421.

22. Allsop K. Ziter FA. Loss of strength and functional decline in Duchenne's Dystrophy. Arch Neurol 1981;38:406-411.

23. Hanson R, Albridge-Smith D, Hume W. Achievements on items of the Griffiths Scales: 1980 compared with 1950. Child Care Health Dev 1980;11:91-104.

24. Ahlstrom G, Gunnarson LG. Disability and quality of life in individuals with muscular dystrophies. Scand J Rehabil Med 1996;28:147-157.

25. Bérard C, Payan C, Hodgkinson I, Fian J. A motor function measure scale for neuromuscular diseases. Construction and validation study. Neuromuscul Disord 2005;15 (7):463-470.

26. Vignos PJ, Archibald KC. Maintenance of ambulation in childhood muscular dystrophy. J Chron Dis 1960;12 (2):273-289.

27. Vignos PJ, Archibald KC, Spencer G. Management of progressive muscula dystrophy of childhood. JAMA 1963;184:89-110.

28. Scott OM, Hyde SA, Goddard C, Jones R, Dubowits V. Effect of exercise in Duchenne muscular dystrophy. Physiother 1981;67(6):174-176.

29. Russman BS, Buncher CR, White M, Samaha FJ, lannaccone ST. Function changes in spinal muscular atrophy II and III. The DCN/ SMA Group. Neurology 1996; $47: 973-976$

30. Lovell DJ, Lindsley CB, Rennebohm RM, Ballinger SH, Bowyer SL, Gianninni $\mathrm{EH}$, et al. Development of validated disease activity and damage indices for the juvenile idiopathic inflammatory myopathies. II The Childhood Myositis Assessment Scale (CMAS): a quantitative toll for the evaluation of muscle function. The Juvenile Dermatomyosistis Disease Activity Collaborative Study Group. Arthritis Rheum 1999;42:2213-2219.

31. Jebsen RH, Taylor N, Trieschmann RB, Trotter MJ. An objective and standardized test of hand function. Arch Phys Med Rehabil 1969;50:311-319.

32. Riberto M, Miyasaki MH, Filho DJ, Sakamoto H, Battistella LR. Reprodutibilidade da versão brasileira da Medida de Independência Funcional. Acta Fisiatr 2001:8(1):45-52

33. Research Foundation, State University of New York: Guide for the Uniform Data System for Medical Rehabilitation, including the Functional Independence Measure for Children (WeeFIM), version 1.5. Buffalo, State University of New York. 1991.

34. Mahoney FI, Barthel DH. Functional evaluation: the Barthel Index. Md State Med J 1965:14:61-65.

35. Jebsen RH, Taylor N, Trieschmann RB, Trotter MJ. Fascioscapulohumera dystrophy natural history study: standardization of testing procedures and reliability of measurement. Phys Ther 1994;74:253-263.

36. Gresham GE Phillips TF Labi MLC. ADL status in stroke: relative merits of three standard indexes. Arch Phys Med Rehabil 1980;61:355-358.

37. Towsend E (ed.). Enabling Occupation - An Occupational Therapy Perspective. Ottawa: Canadian Association of Occupational Therapists, 2002. 